\title{
Rolipram, but not siguazodan or zaprinast, inhibits the excitatory noncholinergic neurotransmission in guinea-pig bronchi
}

\author{
Y. Qian, V. Girard, C.A.E. Martin, M. Molimard, C. Advenier
}

Rolipram, but not siguazodan or zaprinast, inhibits the excitatory noncholinergic neurotransmission in guinea-pig bronchi. Y. Qian, V. Girard C.A.E. Martin, M. Molimard, C. Advenier. OERS Journals Ltd 1994.

ABSTRACT: Theophylline has been reported to inhibit excitatory noncholinergic but not cholinergic-neurotransmission in guinea-pig bronchi. As theophylline might exert this effect through an inhibition of phosphodiesterases (PDE), and since many types of PDE have now been described, the aim of this study was to investigate the effects of three specific inhibitors of PDE on the electrical field stimulation (EFS) of the guinea-pig isolated main bronchus in vitro. The drugs used were siguazodan, rolipram and zaprinast, which specifically inhibit PDE types, III, IV and V, respectively.

Guinea-pig bronchi were stimulated transmurally with biphasic pulses $(16 \mathrm{~Hz}, 1$ $\mathrm{ms}, 320 \mathrm{~mA}$ for $10 \mathrm{~s}$ ) in the presence of indomethacin $10^{-6} \mathrm{M}$ and propranolol $10^{-6}$ M. Two successive contractile responses were observed: a rapid cholinergic contraction, followed by a long-lasting contraction due to a local release of neuropeptides from C-fibre endings.

Rolipram $\left(10^{-9}\right.$ to $\left.10^{-6} \mathrm{M}\right)$ but not siguazodan or zaprinast, inhibited the peptidergic contraction in a concentration-dependent manner. Conversely, the cholinergic response was unaffected. Contractile responses induced by exogenous acetylcholine $\left(10^{-8}\right.$ to $\left.10^{-3} \mathrm{M}\right)$ or $\left[\mathrm{Nle}^{10}\right] \mathrm{NKA}(4-10)\left(10^{-10}\right.$ to $\left.10^{-6} \mathrm{M}\right)$ were also unaffected by rolipram, siguazodan and zaprinast $\left(10^{-7} \mathrm{M}\right)$.

These results demonstrate that concentrations of rolipram, similar to those which inhibit PDE, reduce the release of sensory neuropeptides from $\mathrm{C}$-fibre endings, and suggest that the cyclic adenosine monophosphate (AMP) PDE type IV is specifically involved in this effect, as in other anti-inflammatory effects.

Eur Respir J., 1994, 7, 306-310.
Faculté de Médecine Paris-Ouest Laboratoire de Pharmacologie, Paris, France.

Correspondence: C. Advenier Faculté de Médecine Paris-Ouest Laboratoire de Pharmacologie 15, Rue de l'Ecole de Médecine F-75270 Paris Cedex 06

France

Keywords: C-fibres neuropeptides

phosphodiesterase inhibitors

Received: March 111993

Accepted after revision August 81993
Stimulation of bronchial C-fibres induces bronchoconstriction and inflammation, by means of central reflex pathways and local release of the sensory neuropeptides, substance P, neurokinin A and calcitonin gene-related peptide [1]. These peptides cause multiple effects, including contraction of airway smooth muscle, mucus hypersecretion, increase in microvascular permeability, release of inflammatory mediators, and inflammatory cell chemotaxis [2-4]. These proinflammatory effects may play a role in the pathogenesis of asthma, thereby suggesting that control of the local release of neuropeptides might be effective in the management of this disease.

One experimental approach to C-fibre stimulation and control is the study of guinea-pig bronchial reactivity to electrical field stimulation (EFS) in vitro, since EFS causes both a rapid cholinergic and a long-lasting noncholinergic contraction of bronchial smooth muscle, due to release of sensory neuropeptides from $\mathrm{C}$-fibre endings $[1,5-8]$.
It has been shown that several neural or inflammatory mediators exert marked effects on neurotransmitter release [9]. MANZINI et al. [10] and, more recently, BARLINSKI et al. [11] have observed that theophylline $(10-100 \mu \mathrm{M})$ also inhibited the peptidergic contraction in a concentration-dependent manner, but did not affect the cholinergic response, so that this effect might be involved in the previously reported anti-inflammatory action of this substance [12, 13].

As theophylline might exert its effect through inhibition of phosphodiesterases (PDE) and accumulation of cyclic adenosine monophosphate (cAMP) in the cells, and since many types of phosphodiesterase have now been described $[14,15]$, the aim of this study was to investigate the effects of three specific inhibitors of PDE on the EFS of the guinea-pig main bronchi in vitro. The drugs used were siguazodan, rolipram and zaprinast, which selectively inhibit the phosphodiesterase types III, IV and V, respectively. 


\section{Methods}

\section{Tissue preparation}

Guinea-pig main bronchial rings were obtained from tricoloured Hartley guinea-pigs of either sex (250-350 g) anaesthetized with urethane $\left(1.25 \mathrm{~g} \cdot \mathrm{kg}^{-1}, i . p.\right)$, and were suspended under an initial load of $2.0 \mathrm{~g}$, in Krebs solution, at $37^{\circ} \mathrm{C}$ gassed with $95 \% \mathrm{O}_{2}-5 \% \mathrm{CO}_{2}$. After $1 \mathrm{~h}$ of equilibration, resting force was between 1.5 and $2.0 \mathrm{~g}$. Under these conditions, responses to agonists were reproducible over several hours. Changes in force of contraction were measured isometrically with Pioden strain gauges (UF-1), and amplifiers (Dei Lierre Electronique, France), and displayed on a recorder (Linseis L65514, France). The composition of the Krebs solution was $(\mathrm{mM}): \mathrm{NaCl} 118.0 ; \mathrm{KCl} 5.4 ; \mathrm{CaCl}_{2} 2.5 ; \mathrm{KH}_{2} \mathrm{PO}_{4}$ 1.2; $\mathrm{MgSO}_{4} 1.2 ; \mathrm{NaHCO}_{3} 25.0$ and glucose 11.7.

In all experiments, after $1 \mathrm{~h}$ of rest, guinea-pig bronchial rings were contracted to maximal tension with acetylcholine (ACh) $1 \mathrm{mM}$, and relaxed to maximal relaxation with theophylline $3 \mathrm{mM}$, and then allowed to equilibrate for $60 \mathrm{~min}$ whilst they were washed with Krebs solution every $15 \mathrm{~min}$.

\section{Electrical field stimulation}

Experiments were performed in organ baths, fitted with two platinum plate electrodes $\left(1 \mathrm{~cm}^{2}\right)$ placed alongside the tissue $(10 \mathrm{~mm}$ apart) for transmural EFS (biphasic pulse width $1 \mathrm{~ms}$, constant current of $320 \mathrm{~mA}$ for $10 \mathrm{~s}$ ) $[6,16]$. In all experiments, propranolol $10^{-6} \mathrm{M}$ was added to the buffer solution at the start of the experiment to avoid the influence of adrenergic nerve stimulation, and indomethacin $10^{-6} \mathrm{M}$ was added to the bath to avoid indirect effects of prostaglandins on the neuronal responses. Following the return of the tissue to baseline tone, the preparation was stimulated every $30-45 \mathrm{~min}$, using a stimulator (Dei Lierre Electronique, France) in which the voltage output was adjusted to give a constant current of $320 \mathrm{~mA}$ and which produced biphasic rectangular pulses of alternating polarity. Control experiments $(n=10)$ showed no significant fading of the response to field stimulation during the experimental period. These stimulus parameters caused an optimal reproducible biphasic contraction, which consisted of a fast contraction, followed by a sustained contractile response $[7,8]$. These procedures were repeated in the absence or presence of rolipram $\left(10^{-9}\right.$ to $\left.10^{-6} \mathrm{M}\right)$, siguazodan $\left(10^{-9}\right.$ to $\left.10^{-6} \mathrm{M}\right)$ or zaprinast $\left(10^{-9}\right.$ to $\left.10^{-6} \mathrm{M}\right)$, administered $30 \mathrm{~min}$ before transmural stimulation was applied.

\section{Cumulative concentration-response curves}

The inhibitory effects of rolipram $\left(10^{-7} \mathrm{M}\right)$, siguazodan $\left(10^{-7} \mathrm{M}\right)$ and zaprinast $\left(10^{-7} \mathrm{M}\right)$, used as preventive treatment, were studied. After $30 \mathrm{~min}$ of contact, cumulative concentration-response curves to $\mathrm{ACh}\left(10^{-8}\right.$ to $\left.10^{-3} \mathrm{M}\right)$ or $\left[\mathrm{Nle}^{10}\right] \mathrm{NKA}(4-10)\left(10^{-10}\right.$ to $\left.10^{-6} \mathrm{M}\right)$ were obtained by addition of these compounds every 5-10 min until a plateau was reached. Spasmogen induced contractions were expressed as percentage of maximal contraction induced by control ACh (1 mM). The experiments with $\left[\mathrm{Nle}^{10}\right] \mathrm{NKA}(4-10)$ were performed in the presence of phosphoramidon $\left(10^{-5} \mathrm{M}\right)$ to avoid an inhibition of its effect by metabolism [17]. The effects of zaprinast, siguazodan and rolipram on [Nle $\left.{ }^{10}\right] \mathrm{NKA}(4-10)$ were studied, firstly, because this substance is a selective agonist of neurokinins $\mathrm{NK}_{2}$ receptors and, secondly, because it has been shown that what is principally involved in the guinea-pig bronchial contraction in response to electrical stimulation is stimulation of $\mathrm{NK}_{2}$ receptors $[5,7,8$, $18,19]$.

\section{Statistical analysis of results}

Data are expressed as mean \pm SEM. $\mathrm{EC}_{50}$ values represent the concentration producing $50 \%$ of the maximal effect. Statistical analysis of the results was performed with variance analysis and Student's t-test for paired or unpaired data, as appropriate. Probability values of $\mathrm{p}<0.05$ were considered significant.

\section{Drugs}

The substances used were: acetylcholine $\mathrm{HCl}(\mathrm{PCH}$, Paris, France); indomethacin (Merck); [Nle $\left.{ }^{10}\right] \mathrm{NKA}(4-$ 10) (Novabiochem, Paris, France); propranolol (Sigma, St Louis, USA); rolipram, siguazodan, zaprinast (gift from Rhône Poulenc Rorer, Dagenham, UK); theophylline sodium anisate (Bruneau, Paris, France). All drugs were dissolved in distilled water and then diluted in Krebs solution, except for indomethacin and rolipram, which were dissolved in ethanol, and for siguazodan, which was dissolved in dimethyl sulphoxide (DMSO), and then diluted in Krebs solution. The maximal amount of ethanol or DMSO added to the bath $(0.4 \%)$ did not alter the reactivity of the preparation to acetylcholine.

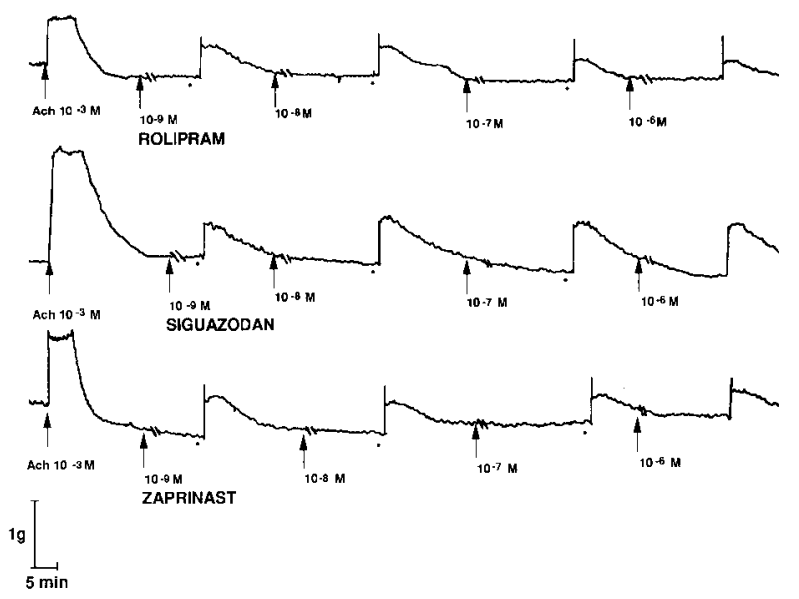

Fig. 1. - Representative traces showing the biphasic response of the guinea-pig isolated main bronchus (propranolol $10^{-6} \mathrm{M}$ and indomethacin $10^{-6} \mathrm{M}$ in the bath) to electrical field stimulation $(\bullet)(\mathrm{EFS})(16 \mathrm{~Hz}, 1$ $\mathrm{ms}, 320 \mathrm{~mA}$ for $10 \mathrm{~s})$ and the effects of rolipram $\left(10^{-9}\right.$ to $\left.10^{-6} \mathrm{M}\right)$ (upper trace), siguazodan $\left(10^{-9}\right.$ to $\left.10^{-6} \mathrm{M}\right)$ (middle trace) and zaprinast $\left(10^{-9}\right.$ to $\left.10^{-6} \mathrm{M}\right)$ (lower trace). Ach: acetylcholine. 


\section{Results}

Figure 1 shows representative traces of the comparative effects of rolipram $\left(10^{-9}\right.$ to $\left.10^{-6} \mathrm{M}\right)$, siguazodan $\left(10^{-9}\right.$ to $\left.10^{-6} \mathrm{M}\right)$ and zaprinast $\left(10^{-9}\right.$ to $\left.10^{-6} \mathrm{M}\right)$ on guineapig bronchial contraction induced by EFS.

Figure 2 shows the results obtained globally in our experiments. The PDE inhibitors tested did not significantly modify the cholinergic response to EFS. Furthermore, it clearly appears that only rolipram, in concentrations of $10^{-8}$ to $10^{-7} \mathrm{M}$, exerts a significant and concentrationdependent inhibitory effect on the late and prolonged guinea-pig bronchial contraction induced by EFS, involving the noncholinergic excitatory system, with 74\% $\left(10^{-7} \mathrm{M}, \mathrm{n}=8\right)$ of inhibition. In contrast, siguazodan and zaprinast did not significantly reduce the noncholinergic response to EFS, reaching only $38 \%\left(10^{-7} \mathrm{M}, \mathrm{n}=9\right)$ and $42 \%\left(10^{-7} \mathrm{M}, \mathrm{n}=7\right)$ of inhibition, respectively.

Figure 3 shows that rolipram $\left(10^{-7} \mathrm{M}\right)$, siguazodan $\left(10^{-7} \mathrm{M}\right)$ and zaprinast $\left(10^{-7} \mathrm{M}\right)$ have no inhibitory effects preventing the contractions induced by $\left[\mathrm{Nle}^{10}\right] \mathrm{NKA}(4-$ 10) and by acetylcholine. In the presence of PDE inhibitors, $\mathrm{EC}_{50}(-\log \mathrm{M})$ of acetylcholine and $\left[\mathrm{Nle}^{10}\right] \mathrm{NKA}(4-10)$ were not significantly different from control (table 1).

a)
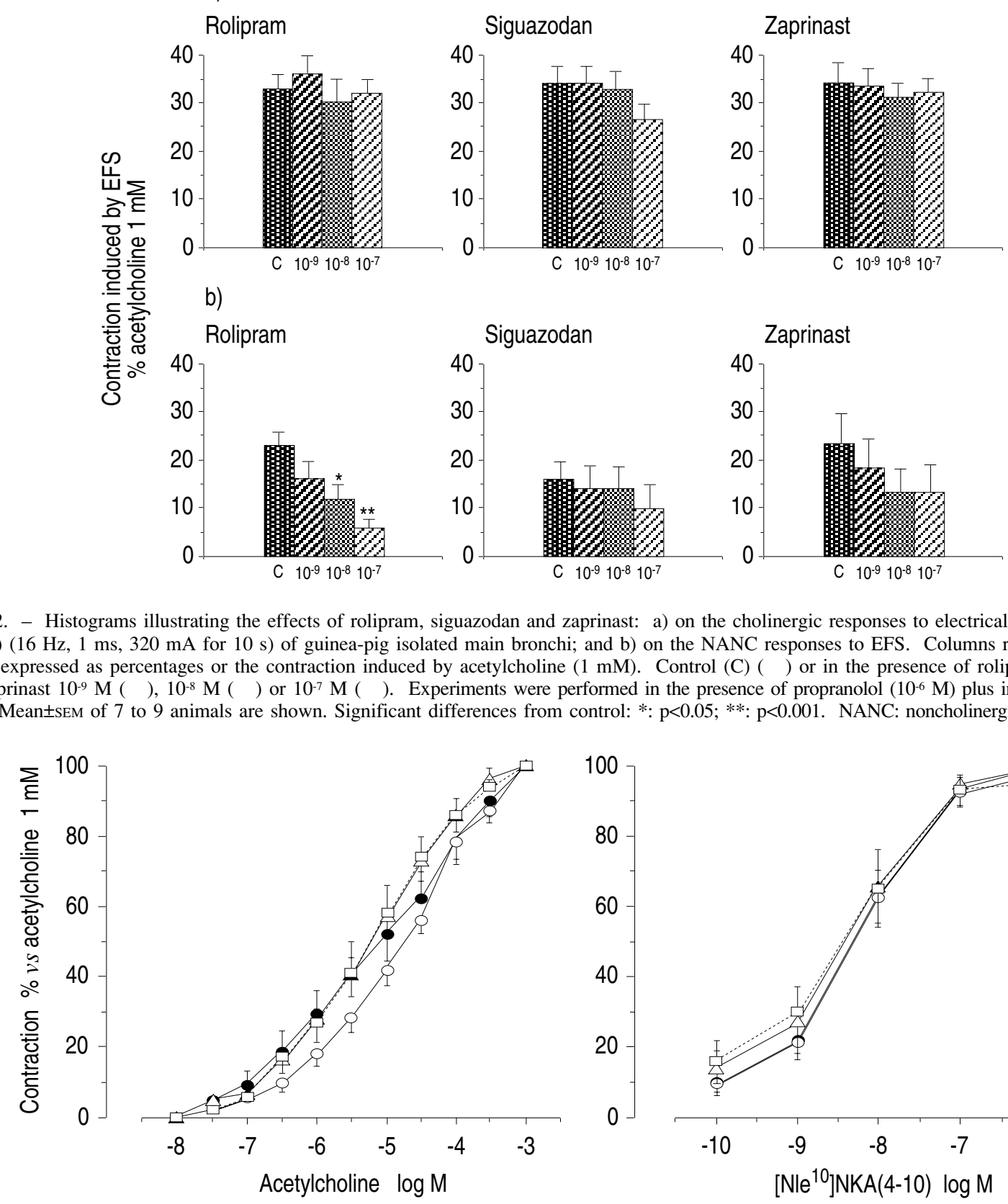

Fig. 2. - Histograms illustrating the effects of rolipram, siguazodan and zaprinast: a) on the cholinergic responses to electrical field stimulation (EFS) $(16 \mathrm{~Hz}, 1 \mathrm{~ms}, 320 \mathrm{~mA}$ for $10 \mathrm{~s})$ of guinea-pig isolated main bronchi; and b) on the NANC responses to EFS. Columns represent contractions expressed as percentages or the contraction induced by acetylcholine $(1 \mathrm{mM})$. Control $(\mathrm{C})(\mathrm{)}$ ) or in the presence of rolipram, siguazodan or zaprinast $10^{-9} \mathrm{M}\left(\right.$ ), $10^{-8} \mathrm{M}(\quad)$ or $10^{-7} \mathrm{M}(\quad)$. Experiments were performed in the presence of propranolol $\left(10^{-6} \mathrm{M}\right)$ plus indomethacin $\left(10^{-6}\right.$ M). Mean \pm SEM of 7 to 9 animals are shown. Significant differences from control: *: $p<0.05 ; * *$ : $<<0.001$. NANC: noncholinergic nonadrenergic.

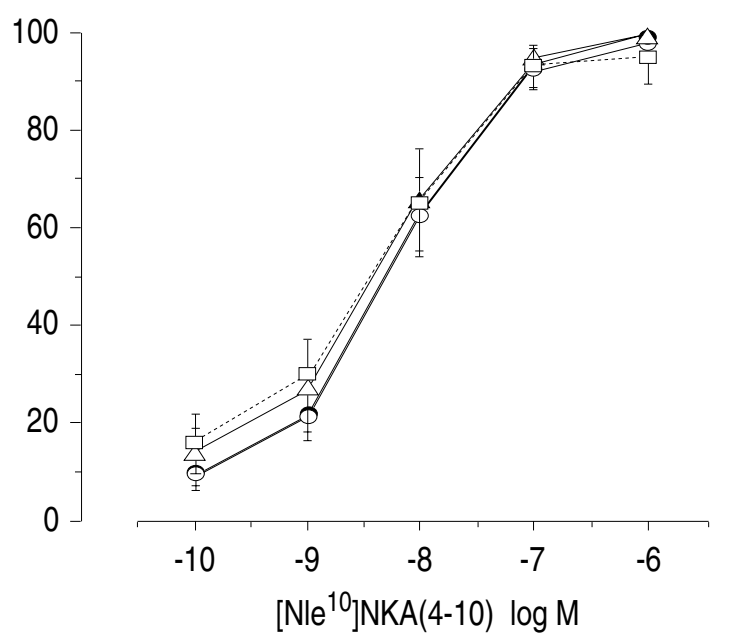

Fig. 3. - Cumulative concentration-response curves for acetylcholine and $\left[\mathrm{Nle}^{10}\right] \mathrm{NKA}(4-10)$. ๑: control; $\bigcirc$ : in presence of rolipram $10^{-7} \mathrm{M}$; $\Delta$ : in presence of siguazodan $10^{-7} \mathrm{M}$; : in presence of zaprinast $10^{-7} \mathrm{M}$. Mean \pm SEM of 4 to 5 animals are shown. No significant difference from control can be shown. 
Table 1. - $-\log \mathrm{EC}_{50}$ values of acetylcholine and [Nle $\left.{ }^{10}\right] \mathrm{NKA}(4-10)$ in the absence (control) or in the presence of rolipram $\left(10^{-7} \mathrm{M}\right)$, siguazodan $\left(10^{-7} \mathrm{M}\right)$ and zaprinast $\left(10^{-7} \mathrm{M}\right)$

\begin{tabular}{lcccc}
\hline Control & $\begin{array}{c}\text { Rolipram } \\
10^{-7} \mathrm{M}\end{array}$ & $\begin{array}{c}\text { Siguazodan } \\
10^{-7} \mathrm{M}\end{array}$ & $\begin{array}{c}\text { Zaprinast } \\
10^{-7} \mathrm{M}\end{array}$ \\
\hline Acetylcholine & $\begin{array}{c}5.14 \pm 0.33 \\
(\mathrm{n}=5)\end{array}$ & $\begin{array}{c}4.92 \pm 0.08 \\
(\mathrm{n}=4)\end{array}$ & $\begin{array}{c}5.20 \pm 0.15 \\
(\mathrm{n}=4)\end{array}$ & $\begin{array}{c}5.19 \pm 0.21 \\
(\mathrm{n}=4)\end{array}$ \\
{$\left[\mathrm{Nle}^{10}\right] \mathrm{NKA}(4-10)$} & $\begin{array}{c}8.24 \pm 0.17 \\
(\mathrm{n}=5)\end{array}$ & $\begin{array}{c}8.24 \pm 0.17 \\
(\mathrm{n}=4)\end{array}$ & $\begin{array}{c}8.38 \pm 0.25 \\
(\mathrm{n}=4)\end{array}$ & $\begin{array}{c}8.36 \pm 0.15 \\
(\mathrm{n}=4)\end{array}$ \\
\hline
\end{tabular}

Data are presented as mean \pm SEM. $\mathrm{EC}_{50}$ : concentration producing $50 \%$ of the maximum effect.

\section{Discussion}

At least five distinct phosphodiesterase isoenzymes are present in mammalian airway smooth muscle cells, each having different selectivities and $\mathrm{Km}$ values of cAMP and cyclic guanosine monophosphate (cGMP). Among these, type III (low Km, cGMP inhibited) and type IV (high $\mathrm{Km}$, cAMP selective) isoenzymes appear to be important for the regulation of cAMP breakdown in airway from guinea-pig, and in canine, bovine or human airways, whereas, type $\mathrm{V}$ is involved in the regulation of cGMP breakdown [14, 15, 20-22].

It has recently been demonstrated that theophylline can inhibit the excitatory noncholinergic neurotransmission in guinea-pig bronchi [11]. Since one of the mechanisms of the theophylline action might be inhibition of PDEs, although theophylline has no specific action on any of the PDE isoenzymes, we endeavoured, in this study, to determine precisely whether inhibition of one of these PDE enzymes was more specifically involved in the inhibition of the excitatory nonadrenergic noncholinergic (NANC) response observed in electrical stimulation of guinea-pig isolated bronchi. For this purpose, we used three specific inhibitors of PDE types III, IV and V, namely siguazodan [23], rolipram [24] and zaprinast [25].

Our results show that only rolipram, in concentrations that inhibit PDEs - thereby potentiating the effects of isoprenaline on the bronchial smooth muscle in guineapigs and man $[26,27]$ - significantly reduces the NANC contraction of guinea-pig bronchi, without having any effect on cholinergic EFS-mediated contraction. One hypothesis to explain the absence of inhibitory effect of rolipram on cholinergic response might be that cholinergic contraction is higher in intensity than the NANC contraction. Additional experiments at low frequencies of stimulation might provide a response. The inhibitory effect of rolipram is not due to a reduced contractile response of bronchial smooth muscle, since exogenous ACh contractions were unaffected. Moreover, the contractile response to $\left[\mathrm{Nle}^{10}\right] \mathrm{NKA}(4-10)$ was also unaffected, suggesting that neither affinity nor responsiveness of receptors was modified by rolipram. Altogether, these results suggest that rolipram reduces the release of neuropeptides from NANC nerve endings.
The absence of inhibitory effect of siguazodan and zaprinast, in comparison to inhibition induced by rolipram, could be explained by a lesser activity of these PDE inhibitors at the concentrations tested. However, it has previously been shown that each of these three PDE inhibitors are approximatively equipotent $\left(\mathrm{EC}_{50}=1 \mu \mathrm{M}\right)$ for their corresponding isoenzymes $[14,15]$.

Under similar conditions, siguazodan and zaprinast, which inhibit PDE III and V, respectively, had no inhibitory effects on these two responses.

Thus, in the airways at least, PDE type IV inhibition may result in an inhibition of local release of neuropeptides. This is of interest for substances to be used in the treatment of asthma and goes side-by-side with other specific and potentially interesting effects of PDE type IV inhibitors, such as inhibition of the microvascular leakage induced by platelet-activating factor (PAF) in the guinea-pig [28, 29], of the N-formylmethionyl-leucylphenylalanine (fMLP)-stimulated superoxide release, and fMLP/thiomerosal elicited leukotriene biosynthesis by human polymorphonuclear leucocytes [30], as well as inhibition of mediator release from human basophils, mast cells, monocytes or neutrophils [31, 32], or of superoxide formation in guinea-pig eosinophils [33].

In conclusion, our results suggest that of the specific inhibitors of PDE tested, only rolipram, an inhibitor of PDE IV subtype, is capable of reducing the release of sensory neuropeptides from C-fibre endings. This property could be an additional component of the antiinflammatory effects described with this type of substance, and of their potential value in the treatment of asthma.

\section{References}

1. Lundberg JM, Saria A. Capsaicin-induced desensitization of airway mucosa to cigarette smoke, mechanical and chemical irritants. Nature 1983; 302: 251-253.

2. Barnes PJ, Baraniuk JN, Belvisi MG. Neuropeptides in the respiratory tract. Am Rev Respir Dis 1991; 144: 1187-1198 (Part I) and 1391-1399 (Part II).

3. Joos GF, Pauwels RA. Mechanisms involved in neurokinin-induced bronchoconstriction. Arch Int Pharmacodyn 1990; 303: 132-146.

4. Frossard N, Advenier C. Tachykinin receptors and the airways. Life Sci 1991; 49: 1941-1953. 
5. Karlsson JA, Finney MJB, Persson CGA, Post C. Substance $\mathrm{P}$ antagonists and the role of tachykinins in noncholinergic bronchoconstriction. Life Sci 1984; 35: 2681-2691.

6. Undem BJ, Myers AC, Barthlow H, Weinreich D. Vagal innervation of guinea-pig bronchial smooth muscle. $J$ Appl Physiol 1990; 69(4): 1336-1346.

7. Maggi CA, Patacchini R, Rovero P, Santicioli P. Tachykinin receptor and noncholinergic bronchoconstriction in the guinea-pig isolated bronchi. Am Rev Respir Dis 1991; 144: 363-367.

8. Martin CAE, Naline E, Emonds-Alt X, Advenier C. Influence of ( \pm -CP-96,345 and SR 48968 on electrical field stimulation of the isolated guinea-pig main bronchus. Eur J Pharmacol 1992; 224: 137-143.

9. Barnes PJ. Modulation of neurotransmission in airways. Physiol Rev 1992; 72(3): 699-729.

10. Manzini S, Conti S, Agostini R, Ballati L. Blockage by theophylline of capsaicin-induced motor effects in guineapig airways. Eur J Pharmacol 1987; 138: 375-383.

11. Barlinski J, Lockhart A, Frossard N. Modulation by theophylline and enprofylline of the excitatory noncholinergic transmission in guinea-pig bronchi. Eur Respir J 1992; 5: 1201-1205.

12. Pauwels R, Van Renterghem D, Van Der Straeten M, Johanneson N, Persson CGA. The effect of theophylline and enprofylline on allergen-induced bronchoconstriction. J Allergy Clin Immunol 1985; 76: 583-590.

13. Pauwels R. The effects of theophylline on airway inflammation. Chest 1987; 92 (Suppl.): 32S-37S.

14. Beavo JA, Reifsnyder DH. Primary sequence of cyclic nucleotide phosphodiesterase isozymes and the design of selective inhibitors. Trends Pharmacol Sci 1990; 11: 150-155.

15. Torphy TJ, Undem BJ. Phosphodiesterase inhibitors: new opportunities for the treatment of asthma. Thorax 1991; 46: 512-523.

16. Szolcsanyi J, Bartho L. Capsaicin-sensitive noncholinergic exitatory innervation of the guinea-pig tracheobronchial smooth muscle. Neurosci Lett 1982; 34: 247-251.

17. Devillier P, Advenier C, Drapeau G, Marsac J, Regoli D. Comparison of the effects of epithelium removal and of an enkephalinase inhibitor on the neurokinin-induced contractions of guinea-pig isolated trachea. Br J Pharmacol 1988; 94: 675-684.

18. Lou YP, Delay-Goyet P, Lundberg JM. Selective inhibition by dactinomycin of NANC sensory bronchoconstriction and [125I]NKA binding due to NK-2 receptor antagonism. Acta Physiol Scand 1992; 144: 221-231.

19. Lundberg JM, Lou YP. Dactinomycin inhibits noncholinergic bronchoconstriction by capsaicin-sensitive sensory nerves in the guinea-pig by antagonizing neurokinin-2 receptor activation. Acta Physiol Scand 1991; 141: 141-142.

20. Nicholson CD, Challiss RAJ, Shahid M. Differential modulation of tissue function and therapeutic potential of selective inhibitors of cyclic nucleotide phosphodi- esterase isoenzymes. Trends Pharmacol Sci 1991; 12: 19-27.

21. Giembycz MA, Belvisi MG, Miura M, Petes MJ, Yacoub $\mathrm{M}$, Barnes PJ. Cyclic nucleotide phosphodiesterases in human trachealis and the mechanical effect of isozyme selective inhibitors. Am Rev Respir Dis 1992; 145: A378.

22. Hall IP, Hill SJ. Effects of isozyme selective phosphodiesterase inhibitors on bovine tracheal smooth muscle tone. Biochem Pharmacol 1992; 43: 15-17.

23. Torphy TJ, Cieslinski LB. Characterization and selective inhibition of cyclic nucleotide phosphodiesterase isoenzymes in canine tracheal smooth muscle. $\mathrm{Mol}$ Pharmacol 1990; 37: 206-214.

24. Reeves ML, Leigh BK, England PK. The identification of a new cyclic nucleotide phosphodiesterase activity in human and guinea-pig cardiac ventricle. Biochem J 1987; 241: 535-541.

25. Weishaar RE, Burrows SD, Kobylarz-Singer DC, Quade MM, Evans DB. Multiple molecular forms of cyclic nucleotide phosphodiesterase in cardiac and smooth muscle and in platelets. Biochem Pharmacol 1986; 35: 787-800.

26. Qian Y, Naline E, Karlsson JA, Raeburn D, Advenier C. Effects of rolipram and siguazodan on the human isolated bronchus and their interaction with isoprenaline and sodium nitroprusside. Br J Pharmacol 1993; 109: 774-778.

27. Zhang Y, Palette-Pays C, Naline E, Varoquaux O, Advenier C. Effect of molsidomine and linsidomine on the human isolated bronchus and the guinea-pig isolated trachea. $J$ Pharm Pharmacol 1993; 45: 280-285.

28. Raeburn D, Karlsson JA. Comparison of the effects of isoenzyme-selective phosphodiesterase inhibitors and theophylline on PAF-induced plasma leak in the guineapig airways in vivo. Am Rev Respir Dis 1992; 145: A612.

29. Ortiz JL, Cortijo J, Vallés JM, Bou J, Morcillo EJ. Rolipram inhibits PAF-induced airway microvascular leakage in guinea-pig: a comparison with milrinone and theophylline. Fund Clin Pharmacol 1992; 6: 247-249.

30. Schudt C, Winder S, Forderkunz S, Hatzelmann A, Ullricu $\mathrm{V}$. Influence of selective phosphodiesterase inhibitors on human neutrophil functions and level of cAMP and Ca. Naunyn Schmiedeberg's Arch Pharmacol 1991; 344: 682-690.

31. Nielson CP, Vestal RE, Sturm RJ, Heaslip R. Effects of selective phosphodiesterase on the polymorphonuclear leukocyte respiratory burst. J Allergy Clin Immunol 1990; 86: 801-808.

32. Peachell PT, Undem BJ, Schleimer RP, et al. Preliminary identification and role of phosphodiesterase isozyme on human basophil. J Immunol 1992; 148: 2503-2510.

33. Dent G, Giembycz MA, Rabe K, Barnes PJ. Inhibition of eosinophil cyclic nucleotide PDE activity and opsonised zymosan-stimulated respiratory burst by "type IV" -selective PDE inhibitors. Br J Pharmacol 1991; 103: 1339_ 1346. 